\title{
The Contribution of Exon-Skipping Events on Chromosome 22 to Protein Coding Diversity
}

\author{
Winston A. Hide, ${ }^{1,3}$ Vladimir N. Babenko, ${ }^{1,2}$ Peter A. van Heusden, \\ Cathal Seoighe, and Janet F. Kelso \\ South African National Bioinformatics Institute, University of the Western Cape, Bellville, South Africa
}

\begin{abstract}
Completion of the human genome sequence provides evidence for a gene count with lower bound 30,000-40,000. Significant protein complexity may derive in part from multiple transcript isoforms. Recent EST based studies have revealed that alternate transcription, including alternative splicing, polyadenylation and transcription start sites, occurs within at least $30-40 \%$ of human genes. Transcript form surveys have yet to integrate the genomic context, expression, frequency, and contribution to protein diversity of isoform variation. We determine here the degree to which protein coding diversity may be influenced by alternate expression of transcripts by exhaustive manual confirmation of genome sequence annotation, and comparison to available transcript data to accurately associate skipped exon isoforms with genomic sequence. Relative expression levels of transcripts are estimated from EST database representation. The rigorous in silico method accurately identifies exon skipping using verified genome sequence. 545 genes have been studied in this first hand-curated assessment of exon skipping on chromosome 22. Combining manual assessment with software screening of exon boundaries provides a highly accurate and internally consistent indication of skipping frequency. 57 of 62 exon skipping events occur in the protein coding regions of 52 genes. A single gene, (FBXO7) expresses an exon repetition. $59 \%$ of highly represented multi-exon genes are likely to express exon-skipped isoforms in ratios that vary from 1:1 to 1:>100. The proportion of all transcripts corresponding to multi-exon genes that exhibit an exon skip is estimated to be $5 \%$.
\end{abstract}

Gene expression products can have variable forms, characterized by alternate start sites of transcription and polyadenylation (Gautheret et al. 1998), exon skipping, and alternate donor and acceptor sites at exon boundaries (Mironov et al. 1999a; Brett et al. 2000; Croft et al. 2000). Exon skipping in transcript isoforms is the most frequent event altering the protein coding sequence of genes (Mironov et al. 1999b; International Human Genome Sequencing Consortium 2001) (http://industry.ebi.ac.uk/ thanaraj/gene.html). Surveys of the incidence of alternative splicing, including exon skipping, have been performed (Andreadis et al. 1987; Iida 1997; Valentine 1998; Thanaraj 1999), and a growing number of anecdotal observations confirm the utilization of exon-skipped transcripts in developmental (Dufour et al. 1998; Lambert de Rouvroit et al. 1999; Lim et al. 1999; Unsworth et al. 1999; Kawahara et al. 2000), tissue-specific (Zacharias et al. 1995), and disease-specific (Jiang and Wu 1999; Mercatante and Kole 2000; Strehler and Zacharias 2001) states.

Several approaches have successfully used hybridization experiments both in silico (Wolfsberg and Landsman 1997; Gautheret et al. 1998; Mironov et al. 1999b; Thanaraj 1999; Beaudoing et al. 2000; Brett et al. 2000; Croft et al. 2000; Schweighhoffer 2000; International Human Genome Sequencing Consortium 2001) and in vitro (Schweighhoffer 2000; Strehler and Zacharias 2001) to assess alternate tran-

\footnotetext{
1These authors contributed equally to this work.

2Present address: Center for Bioinformatics, University of Pennsylvania, Philadelphia, PA, USA.

${ }^{3}$ Corresponding author.

E-MAIL winhide@sanbi.ac.za; FAX

Article and publication are at http://www.genome.org/cgi/doi/10.1101/ gr.188001.
}

script diversity. Nevertheless there are difficulties with interpretation of the results that include (1) the existence of gene families, paralogs, gene copies, and pseudogenes that have similar DNA sequences, providing false positive hybridization; (2) the existence of orphan genes that are located in the complementary strand of intronic or flanking regions (Mironov et al. 1999a); (3) insufficient representation of expressed sequence data in public expressed sequence tag (EST) databases to identify all transcript isoforms.

We have taken an exhaustive approach to the detection of exon skipping from carefully annotated, protein-confirmed genes to maximize the accurate assessment of the degree of isoform diversity.

\section{RESULTS}

To develop an unambiguous assessment of the degree to which exon skipping contributes to expressed transcript isoform diversity, and to assess the impact on protein coding of exon-skipping events within coding regions of transcripts from known genomic loci, we have compared ESTs to 545 annotated genes on chromosome 22 . Although no standard measure of relative spliceform frequencies for human genes exists, coverage of exon boundaries by ESTs provides a measure of the diversity of isoforms for a particular gene. The incidence of captured ESTs spanning exon junctions may also provide a reasonable, though noncomprehensive, view of transcript diversity and expression. Detection of transcripts displaying exon skipping was performed using novel software, j_explorer, which reduced the complexity of the gene sequences to a set of possible splice junctions that were used to search public EST databases to identify ESTs spanning the annotated exon-exon junctions. The software employs 
Table 1. Selection and Exon Structure of Genes for Study

Number of multiple-exon genes selected for study Number of exons

Number of exon junctions

Mean exon length

Minimum exon length observed

Maximum exon length observed

Maximum number of exons observed in one gene

We selected 347 multiple-exon genes of a total 545 genes present on chromosome 22 for study. Those removed included 134 single-exon genes and 64 double-exon genes that could not be assessed for exon skipping.

standard data format (EMBL sequence format) and visualization tools (ARTEMIS, Rutherford et al. 2000) in the analysis (http://www.sanbi.ac.za/exon_skipping/). Removal of single and double exon genes reduced the set to 347 multi-exon genes (Table 1), of which 10 were annotated previously in literature or public databases as having experimentally confirmed exon skips (Table 2). Exon-skipping events were recorded when all original junctions involved in the skipping event, including flanking exons, were confirmed by EST sequences. All ESTs supporting exon-skipping events were subsequently confirmed to be unambiguous transcripts of the corresponding gene and not products of paralogous genes, pseudogenes, or related members of an extended gene family by BLAST searches against the nonredundant (nr) database at NCBI. Highly specific identification of exon-skipping and exon-repetition events has resulted.

Sensitivity was assessed using the 10 genes with experimentally confirmed exon skipping. j_explorer accurately identified the previously reported skipped exons in four of the genes (NF2, ADSL, CLTCL, and GGT1). Novel isoforms were detected in EWSR1, PLA2G6, and GGT1 (Table 2), whereas previously described exon-skipping events in four genes (CACNA1I, BZRP, MTMR3, SEP3) were not detected because ESTs mapping to these exon junctions were not available in the public EST databases. The approach yields zero false positives, as confirmed by available mRNA and genomic data, and provides a solid basis for the development of models of transcript diversity that can be generated from a single gene.

We have discovered 62 exon-skipping events in 52 genes (Table 2); 57 of the 62 (92\%) exon-skipping events occur within the protein-coding region. The remainder occur in either the $3^{\prime}(1 / 62)$ or $5^{\prime}(4 / 62)$ untranslated region (UTR). In $31 / 62(50 \%)$ of cases the reading frame is maintained but regions are deleted. In 18/62 cases (29\%) the introduction of a skip destroys the reading frame resulting in a frame shift. Proteins for the remaining 8/62 (13\%) could not be reconstructed. In four cases an alternative stop codon is used, whereas in five cases there is an alternative start codon introduced.

Gene transcripts were scanned for exon repetition using similarity searching of repeated exon constructs against public EST data. A single tandem repetition of exon 2 of the F-box protein (NM_012179) was detected with high identity to EST AA569698. Exon repetition has only previously been reported in rodents (Frantz et al. 1999).

Ratios of transcript isoforms are difficult to resolve using only EST data, however using the relative capture frequency of skipped exons as a measure provides an indication of the incidence of more commonly occurring isoforms (four or more ESTs confirm the isoform with exon skipping in: CLTCL1, ADSL, GGT1, GSTT1, HMG2L1, MFNG, dJ222E13.1) as compared to rarer isoforms. In $47 / 62$ (76\%) cases, the reference isoform, constructed from the genomic EMBL entry, is represented more frequently than a skipped exon isoform (Table 2).

The degree to which the level of gene expression, and hence database representation, affects the probability of finding a skipped transcript was assessed using the number of EST exon-exon junction captures per gene as a relative measure of transcript representation. Three categories comprising equal gene numbers were selected: low capture, which corresponds to $<14$ EST matches per gene; medium capture, those from 14 to 50 EST matches per gene; and high capture, those with 50 or more EST matches per gene (Table 3). Forty-four genes had no matches to ESTs. We found that 33 have $>50$ EST matches per gene and that $>60 \%$ of genes that demonstrate exon skipping have large numbers of ESTs matching to them. Although no relationship between degree of gene expression and extent of skipping can be determined from this study, the degree to which exon junctions are represented in transcripts reveals that highly represented genes demonstrate skipping more frequently. Ten of the 17 (59\%) most highly represented multiexon genes show exon skipping and of these, three (18\%) express more than one isoform (Table 2, http:// www.sanbi.ac.za/exon_skipping).

To calculate the proportion of mRNAs that may contain a skipped exon we treat each EST spanning an exon junction as an independent sample of the exon junctions. The number of times an EST spans an exon junction is 23,922. The number of times an EST spans a nonconsecutive junction is 149. The number of times an EST spans a consecutive junction is 23,773 . From this we estimate that the probability that a given exon junction in a given mRNA is nonconsecutive is $\sim f=149 / 23,773$. There are 2893 exon junctions in the 347 multi-exon genes, therefore the average number of exon junctions per multi-exon genes is $\mathrm{m}=2893 / 347$. The probability that a given multi-exon mRNA has at least one nonconsecutive exon junction is therefore $1-(1-\mathrm{f})^{\mathrm{m}}=0.051$. As this estimate is derived from a large sample of exon junctions, it may be applicable as a genome-wide estimate.

\section{DISCUSSION}

Our approach precisely identifies exon skipping when EST transcript data that spans exon boundaries is available. The number of ESTs that cover an exon-exon boundary determines the likelihood of discovering an exon skip, but capture of exon-skipping events are dependent on the ratio of lowabundance to high-abundance isoforms of transcripts from the gene. The depth of transcript representation in EST databases, level of expression, and number and length of exons all contribute to the complexity of estimation of the number of genes that may have exon-skipped expressed transcripts. Estimation of the genome-wide extent of exon skipping is supported here by 52 of 347 multi-exon genes $(-15 \%)$. This conservative estimate reflects the fact that only $68 \%$ of exonexon junctions have EST coverage, and that this coverage is skewed towards over-representation of the 3' UTRs. In contrast, 59\% of multi-exon, highly EST-represented genes present exon skipping. If exon skipping is independent of the level of expression of a gene, then $59 \%$ of all multi-exon genes could exhibit skipping. The fact that increasing EST coverage results in the detection of increasing numbers of exon- 
Hide et al.

Table 2. Identification of Chromosome 22 Genes with Unambiguous Transcripts of Exon-Skipped Isoforms

\begin{tabular}{|c|c|c|c|c|c|}
\hline Locus name & $\begin{array}{l}\text { Skipped } \\
\text { exon(s) }\end{array}$ & $\begin{array}{l}\text { Effect of } \\
\text { exon skip }\end{array}$ & $\begin{array}{l}\text { No. ESTs } \\
\text { confirming } \\
\text { exon skip }\end{array}$ & $\begin{array}{l}\text { Average no. ESTs } \\
\text { confirming } \\
\text { reference isoform }\end{array}$ & Database annotation \\
\hline \multicolumn{6}{|c|}{ J_explorer identified an experimentally confirmed isoform } \\
\hline CLTCL1‡ & 29 & $\mathrm{C}+$ & 6 & 4.0 & Clathrin heavy polypeptide-like 1 \\
\hline$A D S L \ddagger^{*}$ & 12 & $3^{\prime}$ & 11 & 63.0 & Adenylosuccinate lyase \\
\hline$N F 2 \ddagger$ & $2-3$ & $\mathrm{Cf} / \mathrm{s}$ & 1 & 5.7 & $\begin{array}{l}\text { Neurofibromatosis } 2 \text { (bilateral } \\
\text { acoustic neuroma) }\end{array}$ \\
\hline \multicolumn{6}{|c|}{ J_explorer identified an experimentally confirmed isoform and a novel isoform } \\
\hline \multirow[t]{3}{*}{ GCT1 } & 7 & $\mathrm{Cf} / \mathrm{s}$ & 2 & - & Gamma-glutamyltransferase 1 \\
\hline & 3 & & 4 & - & \\
\hline & \multicolumn{5}{|c|}{ J_explorer identified a novel isoform and not the experimentally confirmed isoform } \\
\hline PLA2G6 & $3+5$ & $\mathrm{Cf} / \mathrm{s}$ & 2 & 1.5 & Phospholipase A2 groups VI \\
\hline EWS $\ddagger^{*}$ & 6 & $\mathrm{C}+$ & 1 & 48.0 & Ewing sarcoma breakpoint region 1 \\
\hline \multicolumn{6}{|c|}{ Novel exon skipping events identified by J_explorer } \\
\hline \multirow[t]{2}{*}{ ATP6E* } & 2 & $\mathrm{C}+$ & 1 & 73.5 & $\begin{array}{l}\text { ATPase } \mathrm{H}+\text { transporting lysosomal } \\
\text { (vacuolar proton pump) }\end{array}$ \\
\hline & $5-7$ & $C+3^{\prime} t$ & 1 & 38.0 & $31 \mathrm{kD}$ \\
\hline MIL1 & 3 & $\mathrm{C}_{+}$ & 2 & 13.0 & Homo sapiens MIL1 protein \\
\hline UFD1 $1 L^{*}$ & $2-3$ & $C+3^{\prime} t$ & 1 & 21.7 & Ubiquitin fusion-degradation 1-like \\
\hline$T R$ & 13 & $\mathrm{C}+$ & 1 & 6.0 & Thioredoxin reductase beta \\
\hline$A R V C F$ & 19 & $\mathrm{C}+$ & 1 & 1.5 & $\begin{array}{l}\text { Armadillo repeat gene deletes in } \\
\text { velocardiofacial syndrome }\end{array}$ \\
\hline AC005500.4 & $2-3$ & $\mathrm{C}_{+}$ & 1 & 5.4 & Zinc finger protein \\
\hline PIK4CA & $36-42$ & $\mathrm{Cf} / \mathrm{s}$ & 1 & 5.6 & $\begin{array}{l}\text { Phosphatidylinositol 4-kinase } \\
\text { catalytic alpha polypeptide }\end{array}$ \\
\hline$B C R$ & 20 & $\mathrm{Cf} / \mathrm{s}$ & 1 & 5.5 & Active BCR-related gene \\
\hline AP000350.2 & 5 & $\mathrm{C}+$ & 2 & 1.0 & $\begin{array}{l}\text { Similar to glucose transporters } \\
\text { SW:P22732 }\end{array}$ \\
\hline \multirow[t]{3}{*}{ GSTT1 } & 2 & $\mathrm{Cf} / \mathrm{s}$ & 4 & 7.5 & Glutathione S-transferase theta 1 \\
\hline & $2-3$ & $\mathrm{Cf} / \mathrm{s}$ & 1 & 8.0 & \\
\hline & $3-4$ & $\mathrm{C}+$ & 1 & 9.3 & \\
\hline \multirow[t]{2}{*}{ AC004997.1† } & 5 & $\mathrm{CN} / \mathrm{A}$ & 1 & 4.0 & GATS protein \\
\hline & $5-6$ & $\mathrm{C}_{+}$ & 1 & 4.0 & \\
\hline SEC14L2 & 10 & $\mathrm{Cf} / \mathrm{s}$ & 2 & 4.5 & SEC14 (S. cerevisiae)-like 2 \\
\hline SMTN† & $14-15$ & $\mathrm{CN} / \mathrm{A}$ & 1 & 5.7 & Smoothelin \\
\hline d)858B16.1 & 27 & $C+3^{\prime} t$ & 1 & 2.3 & $\begin{array}{l}\text { Homo sapiens mRNA for KIAA0542 } \\
\text { protein complete cds. }\end{array}$ \\
\hline AC005004.1 & $22-23$ & $\mathrm{C}+$ & 2 & 1.7 & $\begin{array}{l}\text { Homo sapiens mRNA for KIAA0645 } \\
\text { protein complete cds }\end{array}$ \\
\hline \multirow[t]{3}{*}{ HMG2L1 } & 2 & $5^{\prime}$ & 4 & 1.5 & $\begin{array}{l}\text { High-mobility group protein } \\
\text { 2-like } 1\end{array}$ \\
\hline & 5 & $5^{\prime}$ & 1 & 4.0 & \\
\hline & $2+5$ & $5^{\prime}$ & 1 & 4.6 & \\
\hline \multirow[t]{2}{*}{ CE132D12.1 } & 6 & $\mathrm{Cf} / \mathrm{s}$ & 1 & 21.5 & Similar to RAS-related protein \\
\hline & 7 & $\mathrm{Cf} / \mathrm{s}$ & 5 & 46.0 & RAB-5A (HS) \\
\hline MFNG $\dagger$ & 2 & $\mathrm{C}_{+}$ & 1 & 16.0 & Manic fringe (Drosophila) homolog \\
\hline LGALS1* & 3 & $\mathrm{Cf} / \mathrm{s}$ & 5 & $>100.0$ & $\begin{array}{l}\text { Lectin galactoside-binding soluble } \\
1 \text { (galectin } 1 \text { ) }\end{array}$ \\
\hline GCAT & $2-3+5$ & $\mathrm{CN} / \mathrm{A}$ & 1 & 2.8 & $\begin{array}{l}\text { Glycine C-acetyltransferase } \\
\text { (2-amino-3-ketobutyrate-CoA } \\
\text { ligase) }\end{array}$ \\
\hline dJ1014D13.1* & 12 & $\mathrm{C}_{+}$ & 1 & $>100.0$ & $\begin{array}{l}\text { Weakly similar to casein kinase } 1 \\
\text { homolog HRR25 }\end{array}$ \\
\hline GTPBP1 & 2 & $C+5^{\prime} t$ & 8 & 17.0 & GTP binding protein 1 \\
\hline d)508I15.1 & 2 & $C+5^{\prime} t$ & 1 & 8.0 & $\begin{array}{l}\text { Novel human gene mapping to } \\
\text { chromosome } 22\end{array}$ \\
\hline d)508I15.4 & 3 & $\mathrm{CN} / \mathrm{A}$ & 1 & 1.5 & $\begin{array}{l}\text { Homo sapiens mRNA for KIAA0668 } \\
\text { protein }\end{array}$ \\
\hline$R P L 3 \dagger^{*}$ & 8 & $\mathrm{C}+$ & 7 & $>100.0$ & Ribosomal protein L3 \\
\hline dJ1042K10.2 & 2 & $C+5^{\prime} t$ & 1 & 10.5 & $\begin{array}{l}\text { Similar to C. elegans predicted } \\
\text { protein with probable rabGAP } \\
\text { domains and src homology }\end{array}$ \\
\hline SLC25A17 & $2-4$ & $\mathrm{Cf} / \mathrm{s}$ & 1 & 9.0 & Solute carrier family 25 \\
\hline & $3-4$ & $\mathrm{C}+$ & 2 & 9.0 & $\begin{array}{l}\text { (mitochondrial } \\
\text { carrier-peroxisomal membrane } \\
\text { protein } 34 \mathrm{kD} \text { ) member } 17\end{array}$ \\
\hline ST13* & 8 & $C \mathrm{f} / \mathrm{s}$ & 1 & 17.5 & $\begin{array}{l}\text { Suppression of tumorigenicity } 13 \\
\text { (Hsp 70-interacting protein) }\end{array}$ \\
\hline
\end{tabular}


Table 2. (Continued)

\begin{tabular}{|c|c|c|c|c|c|}
\hline Locus name & $\begin{array}{l}\text { Skipped } \\
\text { exon(s) }\end{array}$ & $\begin{array}{l}\text { Effect of } \\
\text { exon skip }\end{array}$ & $\begin{array}{l}\text { No. ESTs } \\
\text { confirming } \\
\text { exon skip }\end{array}$ & $\begin{array}{l}\text { Average no. ESTs } \\
\text { confirming } \\
\text { reference isoform }\end{array}$ & Database annotation \\
\hline$R B \times 1$ & $\begin{array}{c}2 \\
3-4\end{array}$ & $\begin{array}{l}C f / s \\
C+3^{\prime} t\end{array}$ & $\begin{array}{l}3 \\
1\end{array}$ & $\begin{array}{l}50.5 \\
92.0\end{array}$ & Ring-box 1 \\
\hline PMM1 & 4 & $\mathrm{Cf} / \mathrm{s}$ & 1 & 24.5 & Phosphomannomutase 1 \\
\hline TCF20 (AR1)† & 3 & $\mathrm{CN} / \mathrm{A}$ & 1 & 5.0 & Transcription factor 20 (AR1) \\
\hline d)222E13.3† & 7 & $\mathrm{Cf} / \mathrm{s}$ & 2 & 12.0 & $\begin{array}{l}\text { Weak match to Arabidopsis RNA } \\
\text { and export factor binding } \\
\text { protein }\end{array}$ \\
\hline dJ222E13.1 & $8-9$ & $\mathrm{Cf} / \mathrm{s}$ & 5 & 2.0 & $\begin{array}{l}\text { Novel protein with some similarity } \\
\text { to Drosophila KRAKEN }\end{array}$ \\
\hline bK1191B2.3† & 3 & $\mathrm{C}_{+}$ & 4 & 2.0 & $\begin{array}{l}\text { Weakly similar to d } 11118 \\
\text { COA-ACYL carrier protein } \\
\text { transacylase }\end{array}$ \\
\hline d]796117.2* & 3 & $\mathrm{C}+$ & 1 & 27.0 & CGI-51 \\
\hline NPAP60L & 4 & $\mathrm{CN} / \mathrm{A}$ & 1 & 11.5 & $\begin{array}{l}\text { Nuclear pore-associated protein } \\
60 \mathrm{~L}\end{array}$ \\
\hline d) $355 C 18.1$ & 9 & $\mathrm{C}+$ & 1 & 1.5 & $\begin{array}{l}\text { Matches KIAA0027 gene with weak } \\
\text { similarity to GTPase activating } \\
\text { protein }\end{array}$ \\
\hline ECGF1 & 5 & $\mathrm{CN} / \mathrm{A}$ & 1 & 3.0 & $\begin{array}{l}\text { Endothelial cell growth factor } 1 \\
\quad \text { (platelet-derived) }\end{array}$ \\
\hline GTSE1 (B99) & 8 & $\mathrm{Cf} / \mathrm{s}$ & 1 & 13.5 & $\begin{array}{l}\text { Homo sapiens G-2 and S-phase } \\
\text { expressed } 1 \text { (GTSE1), }\end{array}$ \\
\hline dJ1163/1.4† & 3 & $\mathrm{C}+$ & 1 & 1.0 & $\begin{array}{l}\text { Novel protein similar to C. elegans } \\
\text { B0035.16 and bacterial tRNA } \\
\text { (5-Methylaminomethyl-2- } \\
\text { thiouridylate)-Methyltransferases }\end{array}$ \\
\hline DGCR2 & $2-3$ & C+ & 1 & 2.3 & $\begin{array}{l}\text { DiGeorge syndrome critical region } \\
\text { gene } 2\end{array}$ \\
\hline AC007050.6 & 2 & $\mathrm{CN} / \mathrm{A}$ & 1 & 11.0 & $\begin{array}{l}\text { Homo sapiens mRNA- from clone } \\
\text { DKFZp434G1017 }\end{array}$ \\
\hline UBE2L3 & 2 & $C+5^{\prime} t$ & 1 & 71.0 & Ubiquitin-conjugating enzyme E2L3 \\
\hline DJ756G23.3 & 5 & $\mathrm{C}+$ & 1 & 2.0 & $\begin{array}{l}\text { Similar to Tr:Q24191 Drosophila } \\
\text { TRANSCRIPTIONAL REPRESSOR } \\
\text { PROTEIN }\end{array}$ \\
\hline bK212A2.1 & 2 & $C+3^{\prime} t$ & 1 & - & $\begin{array}{l}\text { TNF-inducible protein CG12-1 } \\
\text { mRNA }\end{array}$ \\
\hline$G 22 P 1^{*}$ & 3 & C+ & 1 & $>100.0$ & $\begin{array}{l}\text { Thyroid autoantigen } 70 \mathrm{kD} \text { (Ku } \\
\text { antigen) }\end{array}$ \\
\hline
\end{tabular}

We tested 347 multiple-exon genes on Chromosome 22 for exon-skipping events using J_explorer and EST sequences from GenBank 119. Genes in which novel exon skipping events have been identified are ordered according to their relative physical organization along chromosome 22. Genes are identified using the HUGO name if one exists. In the absence of a HUGO identifier, the accession number of the sequence or the Sanger Centre clone name is used. Exon numbering is based on the exon structure of the original EMBL entries obtained from the Sanger Centre. ESTs confirming a skip were required to span both the 3' and 5' flanks of the skipped exon. To calculate the average number of ESTs confirming the reference isoform, the exon flanking ESTs in the reference isoform were totalled and the sum divided by corresponding averaged number of junctions. In cases where the reference isoform was not represented in the public EST databases, the sequence was confirmed using a corresponding experimentally-determined mRNA.

Skip location and context is denoted as follows: (C) skip occurs in protein coding region; (+) ORF remains unchanged; (3') skip occurs in $3^{\prime}$ UTR; (5') skip occurs in $5^{\prime} \mathrm{UTR}$; (f/s) frameshift is introduced by skip; $\left(5^{\prime} t\right)$ alternative start codon is used; $\left(3^{\prime} t\right)$ alternative stop codon is used; (N/A) not possible to reconstruct a protein; $(\dagger)$ genes (eight entries total) with an already-annotated exon skip in EMBL entries; ( $\ddagger$ ) (six entries total) with experimentally-confirmed notation: $2-4$ indicates that exons 2,3 and 4 skipped exons; 2-3 +5 indicates that exons 2, 3 and 5 are skipped. Experimentally confirmed skipping events in the genes CACNA1I, BZRP, MTMR3, and SEP3 had no EST matches and are not included.

skipping events indicates that exon-skipped transcripts are relatively rare. We have estimated the probability of detecting an exon-skipped transcript from a pool of multi-exon transcripts to be $\sim 5 \%$. More sensitive transcript capture techniques may discover exon skipping to be far more widespread than the previous estimates of $\sim 10 \%-20 \%$ (Mironov et al. 1999a; Croft et al. 2000) (http://industry.ebi.ac.uk/ thanaraj/ gene.html), which have been based on EST frequencyindependent measures. Expression studies will clarify the relationship between level of expression and degree of exon skipping in transcripts. The diversity of skipped-exon transcript forms is likely to contribute significantly to the diversity of protein products encoded by the genome, especially because the ratio of skipped isoforms of transcripts appears to vary widely, which is likely to have significant functional impact on the proteins for which they code. At least $50 \%$ of exon skips that we have detected result in in-frame deletions in the predicted protein products. In $29 \%$ of cases, exon skipping results in a disruption of the reading frame which may change or disrupt the function of the protein product. Functional 
Table 3. Capture of Exon Skipping Relative to Expression Representation

\begin{tabular}{lcc}
\hline $\begin{array}{l}\text { Number }(\boldsymbol{n}) \text { of ESTs } \\
\text { matching exon junctions } \\
\text { per gene (interval) }\end{array}$ & $\begin{array}{l}\text { Number } \\
\text { of genes }\end{array}$ & $\begin{array}{c}\text { Number of genes } \\
\text { with skips detected } \\
\text { by J_explorer }\end{array}$ \\
\hline $0<\mathrm{n} \leq 14$ & $101(33 \%)$ & $4(7 \%)$ \\
$14 \leq \mathrm{n} \leq 50$ & $101(33 \%)$ & $17(33 \%)$ \\
$\mathrm{n} \geq 50$ & $101(33 \%)$ & $33(60 \%)$ \\
Total & 303 & 52 \\
\hline
\end{tabular}

roles for these protein isoforms remain to be explored experimentally.

\section{METHODS}

j_explorer (available for download from http:// www.sanbi.ac.za/exon_skipping) was used to assemble exon constructs from mRNA-annotated genomic sequences produced by the Human Chromosome 22 Sequencing Group at the Sanger Centre (Chr22.genes.dna file at http:// www.sanger.ac.uk/HGP/Chr22/cwa_archive/Nature_02-121999/Chr22Genes.tar.gz). Using a 50-bp tag from the 3' terminus of the preceding exon and a 50-bp tag from the 5' terminus of all downstream exons, a set of all consecutive and nonconsecutive exon-exon junctions for each gene was created. Each junction was submitted for similarity searching against dbEST (human) using BLAST 2.0 (Altschul et al. 1990). By combining junctions in a consecutive (i.e., exon 1-exon 2 junction) and nonconsecutive (i.e., exon 1-exon 3 junction) manner the incidence of exon skipping was assessed. A skipping event is reported when an EST is detected that does not contain the exon(s) in question, but does contain an uninterrupted tag made up of $50 \mathrm{bp}$ from each of the flanking exons. Exon repetition was investigated by creating splice junctions composed of the concatenation of the $3^{\prime}$ and 5' 50-bp splice junctions of the same exon. ESTs showing significant $\left(P<1 \times 10^{-40}\right)$ homology to an exon junction were extracted and aligned to the corresponding genomic sequence using sim4 (Florea et al. 1998). To exclude the possibility that ESTs confirming exon-skipping events were the products of paralogous genes or members of gene families, all ESTs identifying exon skipping were confirmed to be unique to a single target gene from Chromosome 22. Both interchromosomal and intrachromosomal specificity of the transcripts was confirmed using BLAST with a cut-off score of $1 \times 10^{-30}$. sim 4 was employed where ambiguous matches were encountered. The resulting 'unambiguous transcripts' can therefore be assigned unambiguously to the correct gene of origin. The effect of these transcripts on the reading frame of the protein for which they code was assessed for frameshifts and in-frame deletions. We have confirmed that the results contain no false positives by manual analysis of all cases of possible misalignments. All exon skips reported by j_explorer therefore represent valid skipping events. The identity and genomic location of each the ESTs was converted into EMBL format and added as annotation to the relevant EMBL sequence file. Sequences were then analyzed using ARTEMIS (Rutherford et al. 2000) and are presented together with supplemental information, annotated EMBL entries, and links to ENSEMBL genes and transcripts at http://www.sanbi.ac.za/exon_skipping. All exon structure annotations for the genes used (both confirmed and predicted) were confirmed by manual inspection to be correct. To prevent the detection of skips as a result of incorrectly annotated exon boundaries we required that an EST spanning consecutive (or linear) exon boundaries was present in addition to the ESTs confirming the skip. All linear junctions that could not be confirmed by ESTs resulted in that junction being excluded from further analysis. To address data consistency, we confirmed that in EMBL release 64 (GenBank 119) and 65 (GenBank 121) $\sim 68 \%$ of splice junctions are covered with an EST. This figure does not vary significantly between the two releases.

To determine the effect of exon skipping on protein production, the genomic sequences of the 52 genes with exonskipping events affecting the coding sequence were compared to the cognate mRNA using sim4. Exon-skipping events in the first or last protein-coding exon were recorded as altering the start/stop codon. A UTR-skipping event was recorded when the exon skipped was located in either the $3^{\prime}$ or $5^{\prime}$ UTR. When the skipped exon was located between two coding exons, framefinder (Slater 2000) was used to predict open reading frames (ORFs) for the ESTs confirming the skip. If the ORF showed homology to the protein isoform then it was considered to be a valid representation of the protein isoform. BLASTX alignment of the EST and the predicted protein was used to determine whether or not the exon-skipping event introduced a frameshift.

\section{ACKNOWLEDGMENTS}

We thank L. Sullivan and M. Ramsay for comments on the manuscript, and S. Bardien-Kruger, T. Broveak, and T-M. Chern for support, suggestions, and helpful discussions throughout the study. This work had financial support from the South African Government through the Department of Arts, Culture, Science, and Technology initiated Innovation Fund Program, grant 32146 (W.A.H.) and the South African National Research Foundation (J.F.K).

The publication costs of this article were defrayed in part by payment of page charges. This article must therefore be hereby marked "advertisement" in accordance with 18 USC section 1734 solely to indicate this fact.

\section{REFERENCES}

Altschul, S.F., Gish, W., Miller, W., Myers, E.W., and Lipman, D.J. 1990. Basic local alignment search tool. J. Mol. Biol. 215: $403-410$.

Andreadis, A., Gallego, M.E., and Nadal-Ginard, B. 1987. Generation of protein isoform diversity by alternative splicing: Mechanistic and biological implications. Annu. Rev. Cell Biol. 3: 207-242.

Beaudoing, E., Freier, S., Wyatt, J.R., Claverie, J.M., and Gautheret, D. 2000. Patterns of variant polyadenylation signal usage in human genes. Genome Res. 10: 1001-1010.

Brett, D., Lehmann, G., Hanke, J., Gross, S., Reich, J., and Bork, P. 2000. EST analysis online: WWW tools for detection of SNPs and alternative splice forms. Trends Genet. 16: 416-418.

Croft, L., Schandorff, S., Clark, F., Burrage, K., Arctander, P., and Mattick, J.S. 2000. ISIS, the intron information system, reveals the high frequency of alternative splicing in the human genome. Nat. Genet. 24: 340-341.

Dufour, C., Weinberger, R.P., Schevzov, G., Jeffrey, P.L., and Gunning, P. 1998. Splicing of two internal and four carboxy-terminal alternative exons in nonmuscle tropomyosin 5 pre-mRNA is independently regulated during development. $J$. Biol. Chem. 273: 18547-18555.

Florea, L., Hartzell, G., Zhang, Z., Rubin, G.M., and Miller, W. 1998. A computer program for aligning a cDNA sequence with a genomic DNA sequence. Genome Res. 8: 967-974.

Frantz, S.A., Thiara, A.S., Lodwick, D., Ng, L.L., Eperon, I.C., and Samani, N.J. 1999. Exon repetition in mRNA. Proc. Natl. Acad. Sci. 96: 5400-5405.

Gautheret, D., Poirot, O., Lopez, F., Audic, S., and Claverie, J.M. 1998. Alternate polyadenylation in human mRNAs: A large-scale analysis by EST clustering. Genome Res. 8: 524-530.

Iida, Y. 1997. A mechanism for unsplicing and exon skipping in human alpha- and beta-globin mutant pre-mRNA splicing. Nucleic Acids Symp. Ser. 183-184.

International Human Genome Sequencing Consortium. 2001. Initial sequencing and analysis of the human genome. Nature 409: 860-921.

Jiang, Z.H. and Wu, J.Y. 1999. Alternative splicing and programmed cell death. Proc. Soc. Exp. Biol. Med. 220: 64-72. 
Kawahara, H., Kasahara, M., Nishiyama, A., Ohsumi, K., Goto, T., Kishimoto, T., Saeki, Y., Yokosawa, H., Shimbara, N., Murata, S., et al. 2000. Developmentally regulated, alternative splicing of the Rpn10 gene generates multiple forms of $26 \mathrm{~S}$ proteasomes. EMBO J. 19: 4144-4153.

Lambert de Rouvroit, C., Bernier, B., Royaux, I., de, B., V, and Goffinet, A.M. 1999. Evolutionarily conserved, alternative splicing of reelin during brain development. Exp. Neurol. 156: $229-238$.

Lim, S., Naisbitt, S., Yoon, J., Hwang, J.I., Suh, P.G., Sheng, M., and Kim, E. 1999. Characterization of the Shank family of synaptic proteins. Multiple genes, alternative splicing, and differential expression in brain and development. J. Biol. Chem. 274: 29510-29518.

Mercatante, D. and Kole, R. 2000. Modification of alternative splicing pathways as a potential approach to chemotherapy. Pharmacol. Ther. 85: 237-243.

Mironov, A.A., Fickett, J.W., and Gelfand, M.S. 1999a. Frequent alternative splicing of human genes. Genome Res. 9: 1288-1293.

Mironov, A.A., Koonin, E.V., Roytberg, M.A., and Gelfand, M.S. 1999b. Computer analysis of transcription regulatory patterns in completely sequenced bacterial genomes. Nucleic Acids Res. 27: 2981-2989.

Rutherford, K., Parkhill, J., Crook, J., Horsnell, T., Rice, P., Rajandream, M.A., and Barrell, B. 2000. Artemis: Sequence visualization and annotation. Bioinformatics 16: 944-945.

Schweighhoffer, F. 2000. Qualitative gene profiling: A novel tool in genomics and pharmacogenomics that deciphers messenger RNA isoforms diversity. Pharmacogenomics 1: 187-197.

Slater, G. 2000. "Algorithms for analysis of ESTs." Ph.D. thesis, University of Cambridge, UK.

Strehler, E.E. and Zacharias, D.A. 2001. Role of alternative splicing in generating isoform diversity among plasma membrane calcium pumps. Physiol Rev. 81: 21-50.

Thanaraj, T.A. 1999. A clean data set of EST-confirmed splice sites from Homo sapiens and standards for clean-up procedures. Nucleic Acids Res. 27: 2627-2637.

Unsworth, B.R., Hayman, G.T., Carroll, A., and Lelkes, P.I. 1999. Tissue-specific alternative mRNA splicing of phenylethanolamine $\mathrm{N}$-methyltransferase (PNMT) during development by intron retention. Int. J. Dev. Neurosci. 17: 45-55.

Valentine, C.R. 1998. The association of nonsense codons with exon skipping. Mutat. Res. 411: 87-117.

Wolfsberg, T.G. and Landsman, D. 1997. A comparison of expressed sequence tags (ESTs) to human genomic sequences. Nucleic Acids Res. 25: 1626-1632.

Zacharias, D.A., Dalrymple, S.J., and Strehler, E.E. 1995. Transcript distribution of plasma membrane $\mathrm{Ca} 2+$ pump isoforms and splice variants in the human brain. Brain Res. Mol. Brain Res. 28: $263-272$.

Received March 9, 2001; accepted in revised form August 24, 2001. 


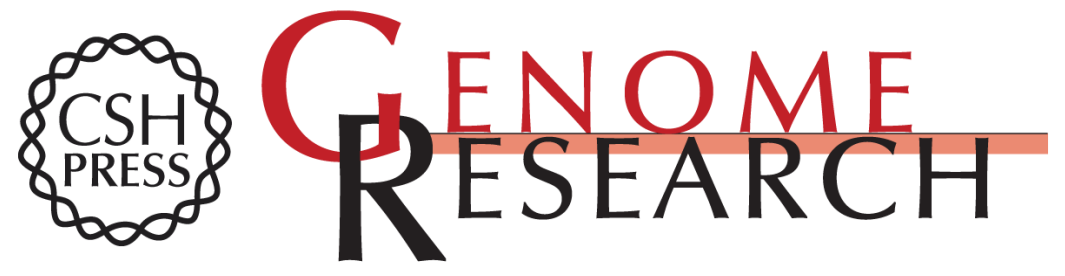

\section{The Contribution of Exon-Skipping Events on Chromosome 22 to Protein Coding Diversity}

Winston A. Hide, Vladimir N. Babenko, Peter A. van Heusden, et al.

Genome Res. 2001 11: 1848-1853

Access the most recent version at doi:10.1101/gr.188001

\section{License}

Email Alerting Service
Receive free email alerts when new articles cite this article - sign up in the box at the top right corner of the article or click here.

\section{Affordable, Accurate Sequencing.}

